\title{
Marc Fumaroli \\ (1932-2020)
}

Tras la vigía o el libelo, no han sido pocas las publicaciones de Francia y el mundo que en junio de 2020 despidieron con algún calificativo altisonante a Marc Fumaroli, uno de los grandes historiadores de la literatura francesa del siglo xx: "Chateaubriand pierde un amigo" (Le Figaro), "Brillante reaccionario de las letras" (La Croix), "Un príncipe del espíritu" (Revue des deux mondes), "La alegría del saber" (El Mundo), "Defensor de la cultura francesa" (The New York Times), "El esteta liberal contra el socialismo cultural" (Contrepoints), "El último profesor" (Le Point), "El antimoderno" (France24), "Más palabras que modas" (Marianne). Han sido pocas las publicaciones-Le Monde entre ellas-que contuvieron sus pasiones al anunciar su fallecimiento y lo cierto es que nada tiene de sorprendente. Marc Fumaroli no solo ha sido uno de los más importantes especialistas en la literatura del inefable siglo XVII francés, escritor de una prosa exquisita y un notable restaurador de la tradición retórica clásica, sino también un irreverente polemista que, bajo el venerable acorazado que proyectaba su erudición, bregaba por la sacralización de la alta cultura y combatía la profanación del arte: "mi cultura es la del alma, no la de las masas", confesó en 2012. Partidario de un "mecenazgo operativo" que, por momentos, recuerda las exhortaciones de Jacques Barzun en La casa del intelecto (1959) y, sobre todo, de Allan Bloom en El cierre de la mente moderna (1987), desde los años 1980, Fumaroli se invistió como el enemigo declarado de una "religión" estatal patrocinada por emblemáticos ministros socialistas de asuntos culturales, quienes, sostuvo, burocratizaron el arte y la cultura a través de un "totalitarismo brechtiano" que instauró el clientelismo populista. En efecto, con la obra
El Estado cultural. Ensayo sobre una religión moderna (1990) su voz comienza a ser conocida por fuera del círculo académico gracias a lo cual termina investido como el mordaz intelectual público de una forma vieillissante y no menos elitista de entender la literatura, el arte y la cultura universitaria. Su defensa de la lengua francesa como un actual reducto de sofisticación ante el imperio del inglés (ampliamente desarrollada en el estudio histórico de 2002, Cuando Europa hablaba francés) y su lucha por la conservación del latín y el griego en la enseñanza secundaria, funcionaban como anticuerpos frente al "fanatismo igualitario" que inauguró la "utopía cultural" del Mayo francés, el cual, según ha lamentado, terminó otorgándole un escandaloso lustre al pop art, al rock y, en suma, a todo el arte contemporáneo tal como lo describe en París-Nueva YorkParís. Viaje al mundo de las artes y de las imágenes (2009). Sin embargo, ese imaginario aristocrático de un mundo ya inexistente, si es que tal mundo alguna vez tuvo lugar, tampoco debería traducirse en un simple batiburrillo liberal (pese al modo en que el público de centro-derecha siempre se ha identificado con sus obras y declaraciones), sino en la nostálgica trinchera de una culture savante que jamás debía ceder ante el mal gusto, ante el consumismo que la cultura del espectáculo trajo consigo, ante la mercantilización de las bellas artes y las belles lettres, ni ante el vampirismo de empresas como Amazon que, entre otras cosas, condenan las ancestrales librerías a una ominosa extinción. En todo caso, cualquier asomo de resistencia libertaria que pueda haber aquí se diluye tras un encomio conservador muy borgesiano que, inevitablemente, se confunde, refracta y da sentido a la zona más erudita de su obra. 
Marc Fumaroli nació en Marsella el 10 de junio de 1932 en el seno de una familia de origen corso, pero con el traslado de su padre como funcionario colonial a Marruecos, se instala en la ciudad de Fez donde pasa toda su infancia y adolescencia. Realiza sus estudios secundarios y el bachillerato en el lycée de Fès-Ville-Neuve donde, desde los 12 años y a instancias de su madre, ya reía con Molière y se extasiaba con Corneille en aras de "recrear mentalmente varias épocas a la vez”. Más allá del mero relato de infancia, hay en la elección de este recuerdo no solo una evocación de su futura predilección por la literatura del siglo XVII, sino un modo de asumir el tiempo histórico, siempre atravesado por la imaginación bibliográfica de un pasado literario cuya sociabilidad intentaba reconstruir, pero también emular en un presente que, no obstante, siempre tuvo algo de inhóspito. De allí, tal vez, que nunca se haya mostrado muy elocuente sobre su vida privada y se haya negado, en más de una ocasión, a escribir sus memorias. Con todo y quizá por esa misma razón, de lo que no cabe ninguna duda es del asiento institucional que, desde un principio, supo darle a su carrera, a juzgar, al menos, por la imperturbable fluidez con la que transita cada instancia académica. Así, de regreso a Francia, cursa el ciclo superior en el lycée Thiers de Marsella, continúa, luego, en la Universidad de Aix-enProvence y en la Sorbona, donde recibe su agrégation en letras clásicas en 1958. Entre septiembre de aquel año y enero de 1961, en plena Guerra de Argelia, realiza el servicio militar en la École militaire interarmes de Coëtquidan y sirve en el VI Regimiento de Artillería en Colbert, en la región de Constantinois. A su regreso, enseña durante dos años en el lycée François-Jean Armorin de Crest en la fantástica zona montañosa de la Vallée de la Drôme. Entre 1963 y 1966, el joven Marc ingresa como pensionista de la prestigiosa Fundación Thiers (donde también se habían alojado Marc Bloch, Michel Foucault o Pierre
Nora), un trienio durante el cual solo quince jóvenes promesas ya graduados (y, por entonces, aún asistidos por un ayuda de cámara), podían continuar con sus investigaciones sin desvelos económicos. Es allí donde prepara una tesis sobre Corneille que publicará un cuarto de siglo más tarde. En 1965, había ingresado como profesor asistente en la Facultad de Lille y, once años después, defenderá su tesis doctoral de Estado en letras con una obra que, tras publicarse en 1980, marcará una inesperada ruptura en los estudios literarios y, en particular, en la historia de la retórica, L’Âge de l'éloquence. Rhétorique et "res literaria" de la Renaissance au seuil de l'époque classique. Allí revela todo un "punto ciego" de operaciones estéticas, juicios artísticos y procesos argumentativos en la literatura de las élites que, bajo los reinados de Luis XIII y Luis XIV, se ven regidos por la presencia aplastante de la elocuencia retórica. Cabe recordar que desde fines de los años 1950 el rescate de la retórica había encontrado, en el ámbito de las ciencias humanas, un clima muy propicio con la circulación de los tratados de argumentación de Chaïm Perelman y Stephen Toulmin, pero también con importantes obras de corte literario, epistemológico y estilístico como los de Brian Vickers, Walter Ong o Andrea Battistini, quienes ya habían advertido la significación de la historia de la retórica en aquellos campos. Sin embargo, el gran mérito de Fumaroli ha sido, en primer término, señalar que durante el Grand siècle las letras y la retórica eran dimensiones indistintas (de allí, la res literaria), consonancia que en el siglo xIx la tradición francesa obliteró tras la conversión de la primera en saber autónomo y la expulsión de la segunda del campo literario, hecho que coincide con la creación en 1894 de la Revue d'histoire littéraire de la France y la desaparición de la retórica de los programas escolares. En segundo lugar, lejos de ser una pieza más del universo cultural del Antiguo Régimen, la elo- 
cuencia retórica era, en realidad, el dispositivo central que ponía en funcionamiento todo el engranaje literario, la producción de ideas y el ejercicio de las instituciones, tanto seculares como eclesiásticas: en definitiva, la "nervadura" que sostenía todo el edificio de la civilización. De tal modo, bajo su impulso, esta nueva línea de investigación (que no solo resignificaba un objeto literario, sino un método para abordarlo) tomará carta de identidad con un coloquio, luego libro, Critique et création littéraires en France au XVII ${ }^{e}$ siècle (1974), con la creación de la Société internationale pour l'histoire de la rhétorique (1977), la publicación de su tesis sobre Corneille bajo el título de Héros et orateurs. Rhétorique et dramaturgie cornéliennes (1990) y, finalmente, con una obra fundamental que, de algún modo, sintetiza este campo del arte, publicada en 1999 bajo su dirección, Histoire de la rhétorique dans l'Europe moderne, 14501950. En este proyecto de largo aliento ya es posible observar de qué modo Fumaroli combinaba una práctica personal y erudita de gran penetración con su disposición colectiva en la formación de investigadores y la responsabilidad en revistas académicas como XVII siècle (que dirigió entre 1978 y 1994) y su intervención pública en diversos medios impresos como Le Point, L'Express, Le Débat, Le Figaro y Le Monde.

En rigor, el proyecto intelectual de Marc Fumaroli consistió en devolverle a la literatura francesa la historicidad perdida tras la hegemonía de un estructuralismo que hizo del texto deshistorizado y la ausencia de autor un bien común, algo que recuerda en el prefacio de la tercera edición de L'Âge de l'éloquence. No es casual, en este sentido, que haya sido discípulo de Raymond Picard -el gran adversario de Roland Barthes- y de quien heredará en junio de 1976, el mismo mes en que defendió la tesis doctoral, su cátedra en la Université Paris-Sorbonne. De tal modo, es innegable que su recuperación de aquel momento precientífico del siglo XVII en que las belles lettres no habían sido fagocitadas por la normalización positivista y la res literaria aún comprendía la elocuencia retórica, es una operación de corte historicista. A este respecto, su obra coincide con la fuerte recomposición que durante los años 1980 llevó a cabo la Escuela de Cambridge al recobrar el contexto ilocutorio de los clásicos del pensamiento político moderno mientras, en los Estados Unidos, Stephen Greenblatt, más atento al mundo social en el marco de un movimiento que dio en llamar, precisamente, neohistoricismo, hacía lo propio con las obras de Shakespeare. Por otro lado, con L'Inspiration du poète de Poussin. Essai sur l'allégorie du Parnasse (1989) y L'École du silence. Le sentiment des images au XVII siècle (1994), Fumaroli comienza a extender la rehabilitación de los contextos sincrónicos a producciones plásticas donde las fuentes antiguas y modernas, junto con la retórica y la mitología se convierten en combinatorias cifradas que permiten recuperar símbolos perdidos y alusiones secretas, modelo que también sigue, cual Vasari moderno, en Le Comte de Caylus et Edme Bouchardon. Deux réformateurs du goût sous Louis XV (2016). Inseparable de su ingente producción ha sido el cursus honorum que legitima una obra monumental, premia institucionalmente una erudición desusada y resguarda la iniciativa de una posición ideológica políticamente incorrecta. A este respecto, prácticamente no hay en Francia (y el mundo occidental) reconocimiento académico u honorífico que se le haya resistido. Más allá de su presencia en la Sorbona hasta su jubilación en 2002, con su ingreso triunfal al Collège de France en 1986 -gracias a los buenos oficios de Yves Bonnefoy y Jean Delumeau-con la cátedra "Rhétorique et société en Europe $\left(\mathrm{XVI}^{\mathrm{e}}-\mathrm{XVII}^{\mathrm{e}}\right.$ siècle)" comienza un ciclo que culminará, como un designio de literatura e historia, en 1995 con su elección en la Académie française donde sucede a Eugène Ionesco 
y en la Académie des Inscriptions et BellesLettres a Georges Duby en 1998. A todo ello debemos añadir una larga serie de presidencias y membresías en sociedades académicas francesas y extranjeras, seminarios en universidades de todo el mundo, varios doctorados honoris causa e ilustres galardones, entre ellos, el Premio Balzan en 2001.

Con todo, de allí también se desprende la representación que Marc Fumaroli construyó de sí. Se trata de un erudito a la vieja usanza que publica obras de una formidable paginación -sus Exercices de lecture. De Rabelais à Valéry (2006) son otra muestra de ello- y produce un tipo de saber tensado por lo nuevo y lo clásico, por rigurosos criterios filológicos propios del mundo contemporáneo y por juicios estéticos de filiación decimonónica que lo llevan a reducir la distancia histórica con figuras del pasado cuya imaginaria familiaridad no quiere perder. Dos trabajos recuperan este ánimo de conversación, La diplomacia del ingenio. De Montaigne a La Fontaine (1994), que supuso una renovación primordial para esta institución literaria, y La República de las Letras (2015), su último trabajo sobre el Grand siècle donde, con indisimulable admiración, recrea las prácticas del otium litteratum. Pero también debemos sumar un tipo de escritura que no amputa su costado de prosa poética porque tal es la clave con la cual, justamente, anuda ambos mundos. Tanto en $L e$ Poète et le roi. Jean de la Fontaine en son siècle (1997) como en Chateaubriand. Poésie et Terreur (2003) se espejan claramente ambas resistencias. En este sentido, recordemos que la obra de Fumaroli ha sido asociada con la historia literaria que practicaron René Pomeau, el gran especialista en Voltaire, o Paul Bénichou (a quien dedica el Chateaubriand). Sin embargo, son otras las filiaciones que ha reclamado para sí, una suerte de heráldica legendaria que lo anclaba en una tradición aun más recóndita. Esa tradición parte de SaintBeuve, continúa con Henri Bremond y cul- mina con Paul Hazard, pero que, a la hora de tomarlos como modelos, se decanta por una restauración de los grandes clásicos que también recuerda los ejercicios de canonización jerárquica de Harold Bloom, con quien comparte su rechazo hacia aquellas letras que hacen de la identidad poscolonial o de género un motivo de producción creativa. Pese a ello, también ha recuperado figuras olvidadas o subestimadas por la historia literaria (tal el caso, por ejemplo, de las Mémoires de Henri de Campion que edita para Mercure de France en 1967 y las Fables de La Fontaine, que presentó y comentó para la Imprimerie nationale en 1985) que, gracias a sus trabajos, adquirieron un valioso protagonismo, rescate que sí lo acerca a la puesta en visibilidad de interlocutores de más bajo perfil, tal como podríamos encontrarlos en un Skinner o en un Pocock. Pero también es cierto que su obra declina aquel historicismo cuando el contexto histórico de producción se erige para universalizar un movimiento francés donde vidas y obras discurren por una larga duración transhistórica que, en más de una ocasión, reniega de la verdadera utilidad de las periodizaciones. Si bien Fumaroli descree de cualquier cometido teleológico, su tratamiento de la literatura es, en este punto, intrínseco a un tipo de reparación eternizante e impresionista (y bastante lejos de Bénichou) donde las figuras célebres y redescubiertas nunca pierden su carácter de perdurable genialidad y son evaluadas a partir de criterios estéticos que permiten actualizar o no su impostergable sitio en el parnaso literario. Y, en este contexto, la celebración de una "excepcionalidad francesa" que se negó a objetivar, nunca dejó de esencializar en buena parte los objetos que indagó. Ello tal vez explique por qué -salvo por su participación en Les Lieux de mémoire, dirigido por Pierre Nora, donde interviene con tres textos "La Coupole", "La conversation" y "Le génie de la langue française"-, no ha dialogado más estrechamente con una historiografía socio- 
cultural con la cual ha compartido intereses análogos. En todo caso, esta concepción derivó en una profunda desconfianza hacia cualquier estilo que se apartase del clasicismo tal como lo fijó Boileau en su Art poétique (1672), cuando clamaba contra el estilo barroco, "evitemos esos excesos y dejemos para Italia la deslumbrante locura de las falsas pedrerías". Al prologar la reedición de Barroco y clasicismo de Victor-Lucien Tapié en 1980, Fumaroli prolonga y reafirma aquel juicio: "delicioso apareamiento entre disciplina universitaria e imaginación novelesca, entre philo lettres y ensueño, escuela de Annales y tu- rismo sentimental". En este sentido, su concepto del arte y la literatura parece no haber cruzado el umbral de una representación mimética como imitación de la realidad, ni tan siquiera en un sentido creativo tal como la entendía Paul Ricœur al cargar con nueva semántica la mímesis en Aristóteles. Y tal vez sea aquella extraña alquimia la que fascina y desconcierta en su obra: el abrumador teatro de una erudición que logra reanimar hasta al más exangüe de sus héroes.

Andrés G. Freijomil

Universidad Nacional de San Martín 